\title{
Influence of the chemical composition on the machinability of brasses
}

\author{
C. Vilarinho ${ }^{\text {a }}$, J.P. Davim ${ }^{\text {b,* }}$, D. Soares ${ }^{\text {a }}$, F. Castro ${ }^{\text {a }}$, J. Barbosa ${ }^{\text {a }}$ \\ ${ }^{a}$ Department of Mechanical Engineering, University of Minho, Campus de Azurém, 4800-058 Guimarães, Portugal \\ $\mathrm{b}$ Department of Mechanical Engineering, University of Aveiro, Campus Santiago, 3810-193 Aveiro, Portugal
}

Received 7 February 2005; accepted 7 May 2005

\begin{abstract}
Although brasses are essentially copper and zinc alloys, they also contain other alloying elements such as lead, silicon, aluminium, iron, tin, manganese, nickel or arsenic whose presence and content are responsible for the wide variety of properties inherent to these materials.

In this article, the effect of the chemical composition of brasses, considering each alloying element and the effective copper content, upon the machinability has been investigated.

For that purpose, machinability tests have been carried out on a CNC lathe under lubricated conditions. The study includes both commercial alloys and samples prepared in laboratory. The experimental procedure consists on turning operations, during which cutting forces and surface roughness obtained in brass workpieces are measured. The chip class is accordingly evaluated.

The statistic treatment of the results enables the establishment of correlations between the studied machinability parameters and the chemical composition of different kinds of brasses.
\end{abstract}

(C) 2005 Elsevier B.V. All rights reserved.

Keywords: Machinability; Brasses; Chemical composition; Cutting forces; Surface roughness; Chips

\section{Introduction}

Machinability refers to the ease or difficulty with which a given material can be machined. Lead is often alloyed to brasses to improve their machinability, enabling it is use for plumbing and bearing applications [1-12]. According to previous research initial lead additions to brasses promote an effective increase in machinability, but for lead contents higher than 3\% no significant improvement is achieved [9]. In fact, concerning brass machinability behaviour, the optimum lead content is usually in the range from 1 to $3 \%$, but this value depends on the volume fraction of $\beta$ and $\alpha$ phases present at the microstructure. $\beta$ phase, as a consequence of its hardness, has a positive effect in machinability, promoting the chip fragmentation of the material in opposition to the $\alpha$ phase that drives to helical and long chips $[7,13]$.

The solubility of lead in copper alloys is very low and for that reason it is found in microstructure as dispersed globules

\footnotetext{
* Corresponding author. Fax: +351234 370953.

E-mail address: pdavim@mec.ua.pt (J.P. Davim).
}

all over the material. It acts as a lubricant decreasing the friction coefficient between the tool and the material, creating discontinuities that promote the chip fragmentation, reducing the cutting force and the tool wear rate [2-9]. Distribution and uniformity of lead globules are a function of cooling rate and play an important role in the reached machinability [12-16]. In the absence of this element production rates are severely limited.

Evaluation of the machinability behaviour is done considering that free-cutting brasses possess a machinability rate standard of 100 . The machinability rate takes into account the chip size, the surface roughness and the consumed power. Examples of these materials are $\mathrm{CuZn} 40 \mathrm{~Pb} 3$ and $\mathrm{CuZn} 36 \mathrm{~Pb} 3$ brasses. Alloys with a machinability rate between 100 and 70 are considered of good machinability, namely CuZn $38 \mathrm{~Pb} 1$, $\mathrm{CuZn} 36 \mathrm{~Pb} 2, \mathrm{CuZn} 39 \mathrm{FeMnSi}$, that are usually employed for brass casting products $[3,17]$.

Besides all the advantages mentioned above, the use of lead must be limited not only because of its deleterious effect on casting properties, namely on shrinkage and hot tearing, but basically because of the growing concern about the 
potential health hazards of this element. As a result of extensive research that indicates that the presence of increase lead content in drinking water can be due to the leaching of leaded copper alloys used for plumbing components, new legislation that compels to a decreasing of the admissible lead content in drinking water during the next years was published $[15,18]$.

In order to fulfil legislation, avoiding the presence of lead in free-machining brasses for the manufacture of plumbing fittings to be used in domestic and industrial potable water supply systems, new alternative alloys were developed, namely by using selenium and bismuth, lead-free copper graphite alloys were synthesized and inorganic and organic coatings proposed $[15,19]$.

The machinability characteristics of Se/Bi alloys, patented as SeBiLLOYS, are comparable to leaded brasses but a main problem arises when using these alloys as an alternative to traditional brasses- $\mathrm{Bi}$ is available in limited quantities and is about ten times the cost of lead $[18,19]$. Additionally some literature shows that $\mathrm{Bi}$ promotes copper and copper alloys embrittlement [19].

Li et al. [20] investigated the adhesion on tools during turning of aluminium bronze. Adhesion was more severe and more uneven on the HSS tool than on the cemented carbide tool YW1. The thickness and the degree of adhesion depend on the temperature distribution on the tool surface.

Recently, Marcos-Barcarena et al. [21] studied the roundness on cylindrical bars turned of aluminium-copper alloys UNS A92024. Macrogeometric deviations of cylindrical work piece are analyzed (roundness) and turned dry under some cutting parameters imposed (cutting velocity and feed). Also an exponential relation between roundness and cutting parameters is established for the turning process of this alloy.

The objective of the present work is to determine the effect of chemical composition on the machinability of brass using both commercial and laboratory prepared alloys, with alloying elements traditionally present on industrial brasses, but used on different contents.

\section{Experimental procedure}

Brasses used in this study were both commercial alloys and alloys produced in the Foundry Laboratory of the Department of Mechanical Engineering of the University of Minho. The last ones include $\mathrm{Cu}-\mathrm{Zn}$ alloys prepared by melting high purity copper and zinc ( $\geq 99.9 \%$ purity) and commercial alloys, both remelted for the addition of alloying elements commonly present in brass compositions, alone or combined, in different contents. For that purpose, a medium frequency induction furnace $(3000 \mathrm{~Hz}$ and $75 \mathrm{~kW})$ was used and after homogenisation the cast alloys were poured into a steel mould in order to obtain cylindrical shaped samples.

As a consequence of the low zinc vapour pressure an efficient control of the furnace power and melting temperature was provided in order to prevent zinc losses. To measure the temperature, a type $\mathrm{K}$ thermocouple, with an accuracy of $\pm 1.5^{\circ} \mathrm{C}$, was used.

The chemical composition of the alloys was determined by X-ray fluorescence spectrometry (XRF) and the hardness value by Rockwell Hardness test.

The machinability tests were carried out by MACTRIBMachining and Tribology Research Group at the Mechanical Technology Laboratory of the University of Aveiro. Machining experiments were performed using a high rigidly lathe Kingsbury50 CNC with $18 \mathrm{~kW}$ spindle power and a maximum spindle speed of $4500 \mathrm{rpm}$.

Samples were machined using a type cemented carbide insert DCMW 11 T3 04 H13A with the following geometry: $0^{\circ}$ rake angle, $7^{\circ}$ clearance angle, $93^{\circ}$ edge major tool cutting and $0^{\circ}$ cutting edge inclination angle. Type SDJCL $2020 \mathrm{~K} 11$ (ISO) tool holder was used.

The following cutting conditions were employed during the cooled tests (emulsion Microtend $231 \mathrm{~L} \mathrm{5 \% )}$ ) for measuring cutting forces and surface roughness: cutting velocity $\left(V_{\mathrm{c}}\right) 165 \mathrm{~m} / \mathrm{min}$, feed rate $(f) 0.1 \mathrm{~mm} / \mathrm{rev}$. and depth of cut (doc) $1.5 \mathrm{~mm}$.

The measurement of the arithmetic roughness average (Ra), the maximum peak to valley height (Rt) and 10-point height $(\mathrm{Rz})$ on turning surfaces, was made by a profilometer Hommelwerke ${ }^{\circledR} \mathrm{T} 1000$, with a cut off of $0.8 \mathrm{~mm}$, according ISO/DIS 4287/1E.

The acquisition of the cutting forces was made by a piezoelectric dynamometer Kistler ${ }^{\circledR} 9121$ connected to a control unit, data acquisition board and microcomputer, capable to measure simultaneously every orthogonal forces developed in turning operations (cutting force (Fz), feed force (Fy) and depth force $(F x)$ ).

The value of machining force $(\mathrm{Fm})$, was calculated according to the following expression:

$\mathrm{Fm}=\sqrt{\mathrm{Fx}^{2}+\mathrm{Fy}^{2}+\mathrm{Fz}^{2}}$

\section{Results and discussion}

The chemical composition, in terms of alloying elements (except zinc) and of effective copper content (ECu), (calculated according to the Guillet expression [14]), the hardness value and the machinability parameters of the studied alloys (concerning the surface roughness, the cutting forces and the chip class according ISO3685:1993 are listed in Table 1.

In order to identify eventual relationships between the chemical composition and the cutting forces and surface roughness of brasses, a regression analysis technique was employed.

\subsection{Surface roughness}

Fig. 1 shows how surface roughness, Ra, Rz and Rt, determined according to ISO 4287/1E, varies with the effective copper content. 
Table 1

Chemical composition (wt\%) except zinc, hardness value and machinability parameters of the alloys produced in this work

\begin{tabular}{|c|c|c|c|c|c|c|c|c|c|c|c|c|c|c|c|c|}
\hline Alloy no. & $\mathrm{Cu}(\%)$ & $\mathrm{Pb}(\%)$ & $\mathrm{Sn}(\%)$ & $\mathrm{Fe}(\%)$ & $\mathrm{Si}(\%)$ & $\mathrm{Al}(\%)$ & $\mathrm{Ni}(\%)$ & $\mathrm{E}_{\mathrm{Cu}}(\%)$ & HRB & $\mathrm{Ra}(\mu \mathrm{m})$ & $\mathrm{Rz}(\mu \mathrm{m})$ & $\mathrm{Rt}(\mu \mathrm{m})$ & $\mathrm{Fx}(\mathrm{N})$ & Fy $(\mathrm{N})$ & $\mathrm{Fz}(\mathrm{N})$ & Chip class \\
\hline 1 & 62.51 & 1.65 & 0.54 & 0.36 & 0.10 & 0.84 & 0.25 & 59.50 & 52 & 0.69 & 4.64 & 5.1 & 20 & 60 & 150 & 6.2 \\
\hline 2 & 61.24 & 2.43 & 0.54 & 0.33 & 0.06 & 2.01 & 0.24 & 55.39 & 76 & 0.86 & 4.48 & 4.9 & 20 & 65 & 170 & 6.2 \\
\hline 3 & 60.97 & 2.32 & 0.53 & 0.33 & 0.06 & 2.88 & 0.24 & 53.06 & 87 & 0.86 & 4.89 & 5.3 & 25 & 95 & 210 & 7.1 \\
\hline 4 & 61.64 & 2.27 & 0.53 & 0.40 & 2.34 & 0.80 & 0.25 & 49.31 & $37^{\mathrm{a}}$ & 0.55 & 4.06 & 6.1 & 40 & 150 & 225 & 6.2 \\
\hline 5 & 61.97 & 2.46 & 0.55 & 0.34 & $<0.05$ & 0.80 & 0.25 & 59.61 & 62 & 0.61 & 4.05 & 4.3 & 20 & 60 & 170 & 7.1 \\
\hline 6 & 60.21 & 4.23 & 1.08 & 0.33 & 0.06 & 1.57 & 0.24 & 55.28 & 72 & 0.86 & 4.67 & 5.1 & 20 & 60 & 150 & 7.1 \\
\hline 7 & 59.20 & 0.95 & $<0.02$ & 0.07 & $<0.05$ & 1.01 & $<0.02$ & 56.36 & 69 & 0.88 & 4.72 & 4.9 & 30 & 70 & 190 & 6.2 \\
\hline 8 & 59.29 & $<0.05$ & 0.78 & $<0.02$ & $<0.05$ & $<0.05$ & $<0.02$ & 58.83 & 61 & 0.72 & 3.90 & 4.2 & 75 & 150 & 300 & 4.3 \\
\hline 9 & 67.04 & $<0.05$ & 0.85 & $<0.02$ & $<0.05$ & $<0.05$ & $<0.02$ & 66.47 & 48 & 1.19 & 5.89 & 6.2 & 40 & 170 & 300 & 4.2 \\
\hline 10 & 66.71 & $<0.05$ & 1.39 & $<0.02$ & $<0.05$ & $<0.05$ & $<0.02$ & 65.80 & 50 & 0.79 & 4.93 & 5.3 & 45 & 160 & 275 & 4.1 \\
\hline 11 & 66.69 & $<0.05$ & 1.78 & $<0.02$ & $<0.05$ & $<0.05$ & $<0.02$ & 65.52 & 53 & 0.92 & 4.55 & 4.7 & 35 & 160 & 280 & 4.2 \\
\hline 12 & 64.83 & $<0.05$ & 0.95 & $<0.02$ & $<0.05$ & $<0.05$ & $<0.02$ & 64.22 & 53 & 0.77 & 4.43 & 5.0 & 40 & 170 & 280 & 4.1 \\
\hline 13 & 61.24 & $<0.05$ & $<0.02$ & $<0.02$ & $<0.05$ & $<0.05$ & $<0.02$ & 61.24 & 53 & 0.96 & 4.78 & 5.1 & 40 & 165 & 280 & 4.3 \\
\hline 14 & 61.04 & $<0.05$ & 0.76 & $<0.02$ & $<0.05$ & $<0.05$ & $<0.02$ & 60.58 & 55 & 1.00 & 4.83 & 5.6 & 40 & 170 & 280 & 2.3 \\
\hline 15 & 55.54 & $<0.05$ & 0.02 & $<0.02$ & $<0.05$ & $<0.05$ & $<0.02$ & 55.53 & 66 & 0.69 & 3.48 & 3.6 & 50 & 150 & 275 & 4.3 \\
\hline 16 & 56.55 & $<0.05$ & 3.84 & $<0.02$ & $<0.05$ & $<0.05$ & $<0.02$ & 54.46 & 93 & 0.70 & 3.58 & 3.8 & 40 & 140 & 250 & 2.2 \\
\hline 17 & 55.37 & $<0.05$ & 5.30 & $<0.02$ & $<0.05$ & $<0.05$ & $<0.02$ & 52.58 & 98 & 0.71 & 3.73 & - & 40 & 125 & 240 & 2.2 \\
\hline 18 & 58.10 & $<0.05$ & $<0.02$ & 0.49 & $<0.05$ & $<0.05$ & $<0.02$ & 58.13 & 58 & 1.08 & 5.26 & 6.0 & 40 & 160 & 280 & 4.3 \\
\hline 19 & 58.83 & $<0.05$ & $<0.02$ & 0.90 & $<0.05$ & $<0.05$ & $<0.02$ & 58.88 & 58 & 0.59 & 3.61 & 4.0 & 45 & 170 & 280 & 1.3 \\
\hline 20 & 61.15 & $<0.05$ & $<0.02$ & 0.46 & $<0.05$ & $<0.05$ & $<0.02$ & 61.18 & 52 & 0.77 & 4.39 & 4.6 & 45 & 180 & 280 & 4.3 \\
\hline 21 & 61.33 & $<0.05$ & $<0.02$ & $<0.02$ & $<0.05$ & 0.49 & $<0.02$ & 59.86 & 50 & 0.86 & 4.39 & 4.9 & 45 & 125 & 270 & 4.3 \\
\hline 22 & 60.82 & $<0.05$ & $<0.02$ & $<0.02$ & $<0.05$ & 1.60 & $<0.02$ & 56.31 & 78 & 0.77 & 5.00 & 5.5 & 40 & 165 & 300 & 4.3 \\
\hline 23 & 61.35 & $<0.05$ & $<0.02$ & $<0.02$ & $<0.05$ & 3.37 & $<0.02$ & 52.50 & 89 & 0.69 & 4.08 & 4.3 & 45 & 160 & 325 & 2.3 \\
\hline 24 & 59.63 & $<0.05$ & $<0.02$ & $<0.02$ & $<0.05$ & 0.54 & $<0.02$ & 58.06 & 56 & 0.86 & 6.06 & 7.4 & 45 & 140 & 260 & 4.3 \\
\hline 25 & 59.38 & $<0.05$ & $<0.02$ & $<0.02$ & $<0.05$ & 1.09 & $<0.02$ & 56.31 & 75 & 1.12 & 5.13 & 5.7 & 50 & 160 & 280 & 2.3 \\
\hline 26 & 58.72 & $<0.05$ & $<0.02$ & $<0.02$ & $<0.05$ & 3.68 & $<0.02$ & 49.59 & 92 & 0.77 & 4.54 & 5.2 & 40 & 160 & 325 & 6.2 \\
\hline 27 & 60.50 & $<0.05$ & 1.04 & $<0.02$ & $<0.05$ & 0.00 & $<0.02$ & 59.88 & 63 & 0.71 & 4.17 & 4.6 & 40 & 150 & 270 & 2.2 \\
\hline
\end{tabular}

a Accuracy of the determinations was $\pm 0.4 \%$ for copper and $0.02 \%$ for the others elements.

The statistical treatment of the results did not enable the establishment of a significative correlation between the surface roughness of the test specimens and it is chemical composition expressed in terms of effective copper content. The same results were obtained with the multivariate analysis in order to each element present in the studied brasses. These results seem to be in accordance with several authors who refer that the surface roughness of the alloys, after machining, is independent of their chemical composition [3].

\subsection{Cutting forces}

Similarly to the surface roughness, no significant correlation was obtained between the cutting forces and the

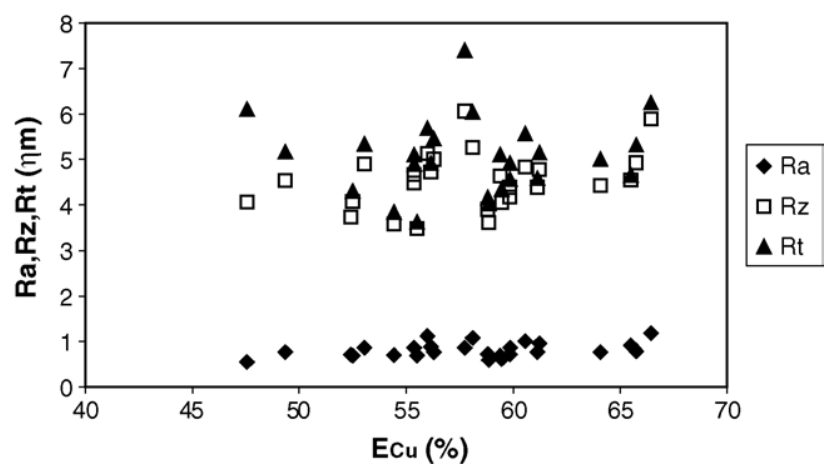

Fig. 1. Surface roughness vs. effective copper content. effective copper content, for every studied alloys. However, with regression analysis techniques it has been possible to estimate several relationships between the alloying elements present in chemical composition of brasses and the cutting forces (Table 2).

The $r^{2}$ values reveal the existence of a strong dependence between the lead content and the machining forces. This is the only alloying element that affects, in a significant way, the three force components. This observation is in agreement with several authors [14,15] who indicate lead as the main responsible for the machinability improvement of brasses as consequence of its lubricant effect and the formation of short and discontinue chips. Silicon and aluminium seem to provide significative changes in some of the cutting forces although they have no effect when considering the resulting force (machining force$\mathrm{Fm})$.

Table 2

Expressions in the form of $F(\mathrm{~N})=A+B \times(\% \mathrm{~Pb})+C \times(\% \mathrm{Si})+D \times(\% \mathrm{Al})$, determined by regression analysis, indicating the relationship between the cutting forces and the chemical composition of brasses

\begin{tabular}{lccccc}
\hline Force $(\mathrm{N})$ & $A$ & $B$ & $C$ & $D$ & $r^{2}$ \\
\hline Fx & 43.6 & -7.2 & - & - & 0.50 \\
Fy & 153.4 & -31.4 & 28.2 & - & 0.72 \\
Fz & 272.7 & -41.6 & - & 11.6 & 0.77 \\
Fm & 197.3 & -11.2 & - & - & 0.99 \\
\hline
\end{tabular}




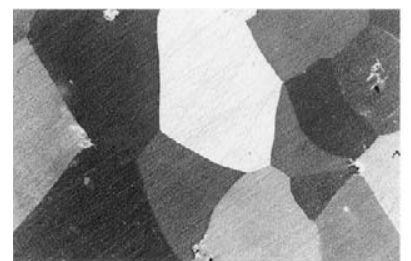

(a)

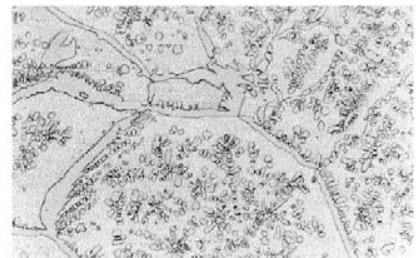

(b)

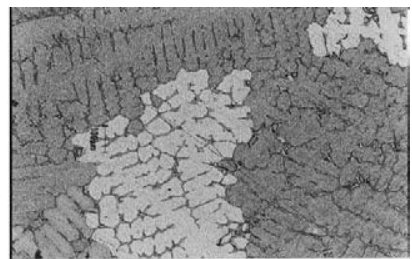

(c)

Fig. 2. Effect of tin additions in the microstructure of $\mathrm{Cu}-\mathrm{Zn}$ base alloys.

\subsubsection{Commercial alloys}

Results presented in Table 1 also reveal that commercial brasses, with or without additions of alloying elements, need lower values of cutting force $(\mathrm{Fz})$ than those demanded by the alloys of the ternary systems, $\mathrm{Cu}-\mathrm{Sn}-\mathrm{Zn}, \mathrm{Al}-\mathrm{Cu}-\mathrm{Zn}$ and $\mathrm{Cu}-\mathrm{Fe}-\mathrm{Zn}$, studied in the present work. Concerning feed and depth forces, some alloys of the systems mentioned above have shown similar or lower values than those presented by some of the commercial alloys submitted to additions. However, the lowest values for these two force machining components were obtained in the group of commercial alloys without additions, traditionally used in casting brass products.

The addition of alloying elements usually present in brasses, namely aluminium and silicon, to commercial alloys increases the cutting forces (Fx, Fy and Fz) as a consequence of microstructural changes. In fact, most of the studied commercial brasses presents a $(\alpha+\beta)$ biphasic structure, with different volume fraction of each phase. Exceptions are the alloys no. 3 and 4 , with a totally $\beta$ phase structure and a $\beta+$ Si rich phase structure, respectively, alloys at which correspond the higher machining forces. However, for $(\alpha+\beta)$ brasses, the negative effect that some alloying elements have on machinable behaviour, namely those that increases the volume fraction of $\beta$ phase, could be balanced by using a higher lead content, as it happens on alloy no. 6.

For commercial alloys, only a correlation between the effective copper content $(\mathrm{ECu})$ and the feed force (Fy) has been observed, expressed by the following expression:

$$
\mathrm{Fy}=495.77-7.53 \times \mathrm{ECu}(\%) \quad\left(r^{2}=0.85\right)
$$

\subsubsection{Alloys from $\mathrm{Cu}-\mathrm{Sn}-\mathrm{Zn}$ system}

In what concern pure alloys, the alloying elements and the tested compositions have lead to significative microstructure changes, with machining behaviour implications.

Tin additions to $\mathrm{Cu}-\mathrm{Zn}$ alloys rise the volume fraction of $\beta$ phase in $(\alpha+\beta)$ structures, lead to a unique $\beta$ phase structure formation (Fig. 2a), and to the development of a $\gamma 1$ phase that, function of the $\mathrm{Cu} / \mathrm{Zn}$ ratio of the alloys, can exist with $\beta$ or $\alpha$ phase (Fig. $2 b$ and c).

Fig. 3 shows the influence of the effective copper content and tin content on cutting and feed forces. It was verified that tin, when present in contents that drives to a $\beta+\gamma 1$ structure, confers to the studied alloys of the $\mathrm{Cu}-\mathrm{Sn}-\mathrm{Zn}$ system the lowest values for Fz and Fy.

The regression analysis technique did not enable the establishment of a relationship between the effective copper content of these alloys and it is machinability behaviour, in contrast with the tin content that seems to play an important role, according to the following expressions:

$$
\begin{array}{ll}
\mathrm{Fz}=295.3-11.0 \times(\% \mathrm{Sn}) & \left(r^{2}=0.78\right) \\
\mathrm{Fy}=170.2-8.2 \times(\% \mathrm{Sn}) & \left(r^{2}=0.74\right)
\end{array}
$$

Concerning thrust force, the alloys of this ternary system present similar values and no correlation with the effective copper content and with tin content have been observed.

\subsubsection{Alloys from $\mathrm{Al}-\mathrm{Cu}-\mathrm{Zn}$ system}

In $(\alpha+\beta)$ biphasic brasses of the $\mathrm{Al}-\mathrm{Cu}-\mathrm{Zn}$ system, the increasing of $\mathrm{Al}$ content with the $\beta$ phase volume fraction increment, raise the cutting and the feed forces, Fig. 4.
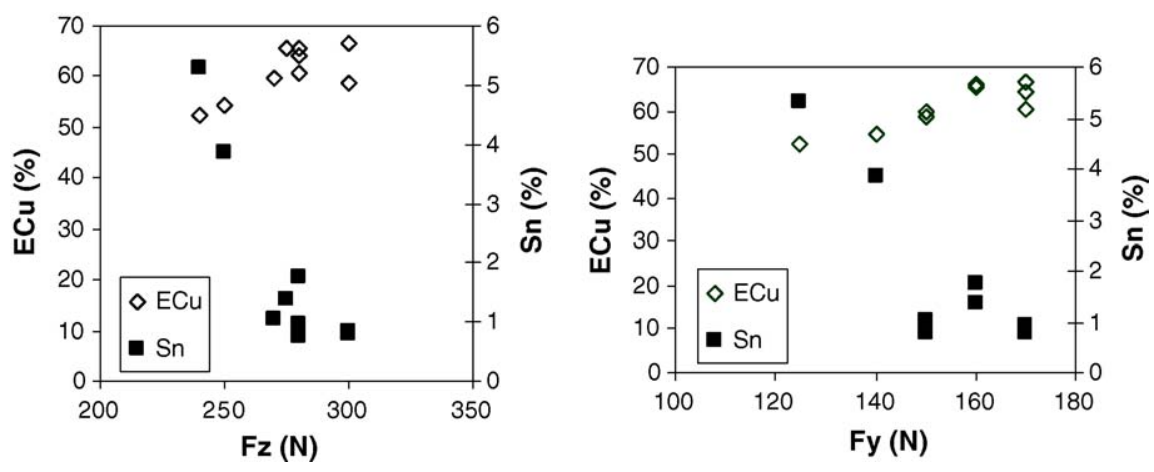

Fig. 3. Cutting force (Fz) and feed force (Fy) vs. effective copper content and tin content, for the studied alloys of the Cu-Zn-Sn system. 

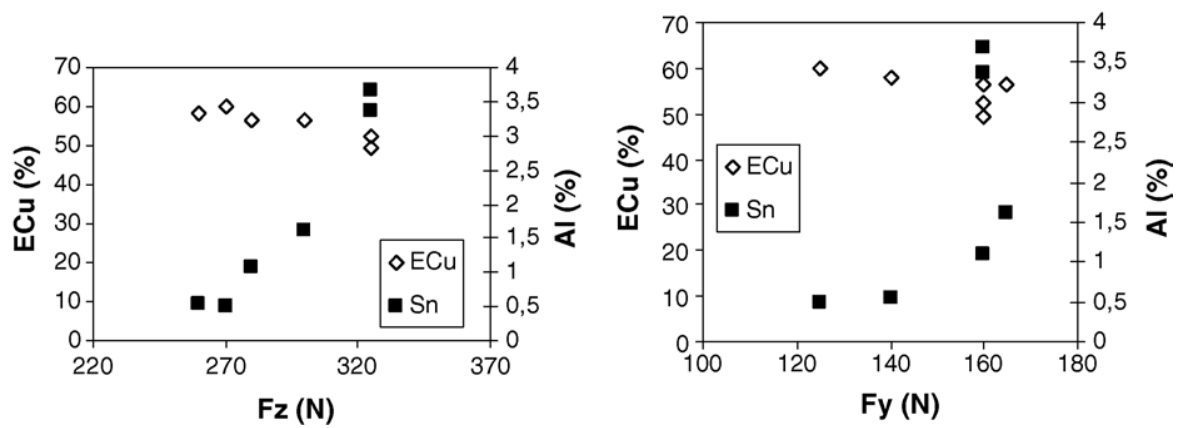

Fig. 4. Cutting force (Fz) and Feed force (Fy) vs. effective copper content and aluminium content, for the studied alloys of the $\mathrm{Cu}-\mathrm{Zn}-\mathrm{Al}$ system.

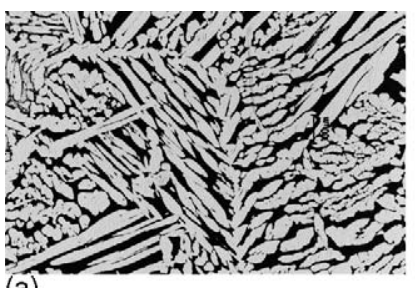

(a)

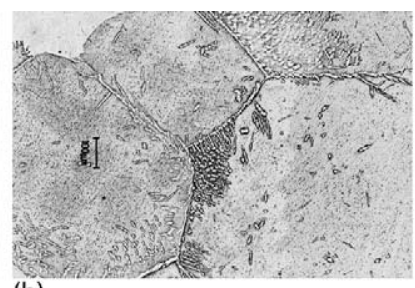

(b)

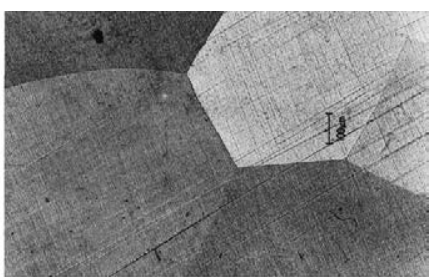

(c)

Fig. 5. Effect of aluminium additions in the microstructure of $\mathrm{Cu}-\mathrm{Zn}$ base alloys

Additional $\mathrm{Al}$ contents may promote a unique $\beta$ phase or a $\beta+\gamma$ structure, with the consequent increase of the cutting force $(\mathrm{Fz})$. Concerning Fy, no relevant effect was detected when the mentioned above phases are present in the alloys microstructure, when compared with the feed force values presented by the alloys of this system showing a $(\alpha+\beta)$ biphasic structure.

In Fig. 5, it is possible to observe the microstructural changes carried through by the aluminium addition to a $\mathrm{Cu} / \mathrm{Zn}$ base alloy (5a). Its presence promotes the reduction of the $\alpha$ phase present $(5 b)$ until its total extinguishing $(5 c)$.

No correlation between the thrust force (Fx) and the $\mathrm{Al}$ content of the studied alloys was found.

The statistical treatment enable the establishment of a strong relationship between the aluminium content and the cutting force:

$\mathrm{Fz}=258.7+19.3 \times(\% \mathrm{Al}) \quad\left(r^{2}=0.94\right)$

\subsubsection{Alloys from $\mathrm{Cu}-\mathrm{Fe}-\mathrm{Zn}$ system}

Concerning the alloys with iron concentration between 0.5 and $1 \%$, for two different $\mathrm{Cu} / \mathrm{Zn}$ ratios, no relationship was found between cutting forces and the iron content. However, the values obtained for the studied alloys of this system, that present in their microstructure $\alpha$ and $\beta$ phases as well as an isolated iron rich phase as show in Fig. 6, are greater than those shown by commercial brasses.

\subsection{Hardness influence in machining properties}

The statistical treatment of the results, considering every alloy of this study, did not enable the establishment of sig- nificant correlation between the materials hardness and the components of the cutting forces needed in machining operations. However, using regression analysis techniques, it has been possible to determine several relationships between this mechanical property and the machinability behaviour of both commercial and pure alloys. Results presented in Table 1 show that the low cutting forces demanded by almost all of the commercial alloys are not a consequence of its hardness, but are due to the presence of lead in it is composition.

\subsubsection{Commercial alloys}

For these alloys, mostly with a $\alpha+\beta$ structure, with different volume fraction of each phase, no relation was found between the cutting forces and the hardness values.

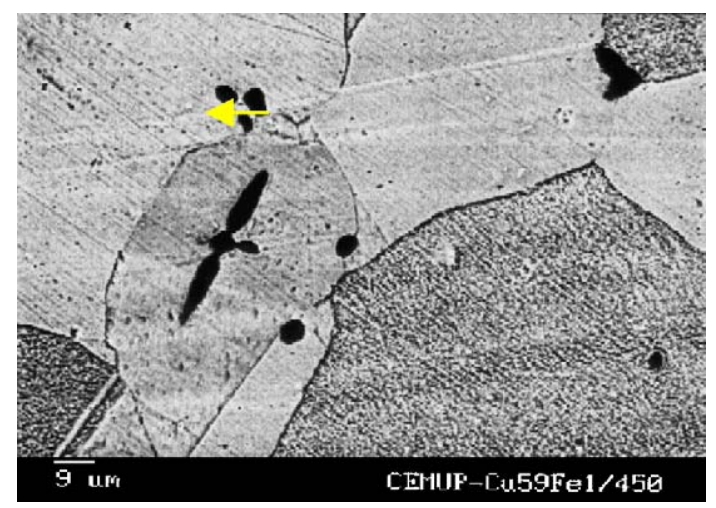

Fig. 6. Iron rich phase present at the microstructure of a studied alloy of the $\mathrm{Cu}-\mathrm{Zn}-\mathrm{Fe}$ system. 


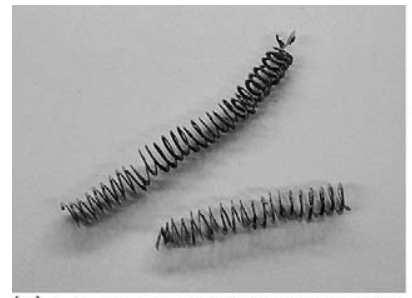

(a) 4.1-Long washer-type helical chips

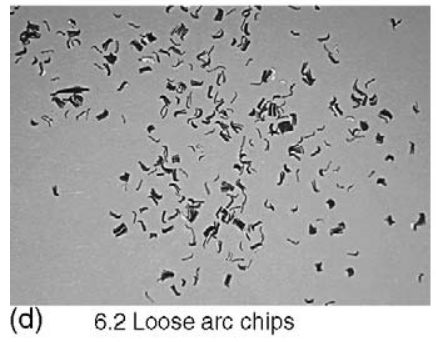

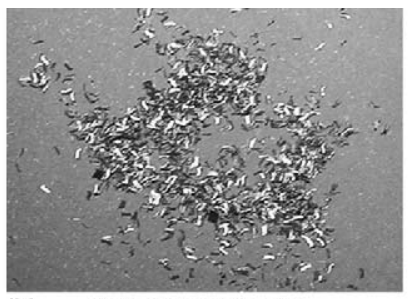

(b) 7.1-Elemental chips

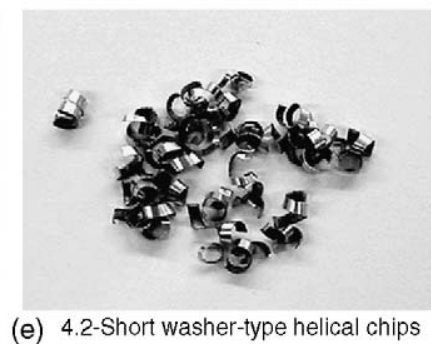

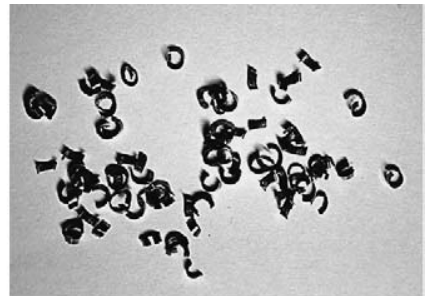

(c) 2.2-Short tubular chips

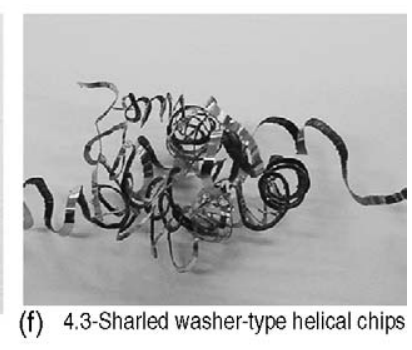

Fig. 7. Some of the chips type formed during machining of brasses with different chemical composition.

\subsubsection{Alloys from $\mathrm{Cu}-\mathrm{Sn}-\mathrm{Zn}$ system}

The hardness values seem to play an important role in the machinability behaviour of these ternary alloys, namely in what concerns to the cutting and feed forces, according with the following expressions:

$$
\begin{aligned}
& \mathrm{Fz}=332.3-0.89 \times(\text { HRB value }) \quad\left(r^{2}=0.73\right) \\
& \text { Fy }=204.2-0.76 \times(\text { HRB value }) \quad\left(r^{2}=0.85\right)
\end{aligned}
$$

The maximum hardness values were obtained for alloys with a $\beta+\gamma 1$ structure.

\subsubsection{Alloys from $\mathrm{Al}-\mathrm{Cu}-\mathrm{Zn}$ system}

For this alloys, it has been possible to establish a correlation between the hardness values and the cutting and feed forces involved in machining operations:

$$
\begin{aligned}
& \mathrm{Fz}=182.2+1.52 \times(\mathrm{HRB} \text { value }) \quad\left(r^{2}=0.87\right) \\
& \text { Fy }=92.2+0.81 \times(\mathrm{HRB} \text { value }) \quad\left(r^{2}=0.78\right)
\end{aligned}
$$

As it can be seen, the effect of aluminium, concerning the alloys machinability behaviour, has an opposite effect to the tin presence. The maximum hardness values were obtained for alloys constituted by $\beta+\gamma 1$ phases.

As well as for the alloys from the $\mathrm{Cu}-\mathrm{Sn}-\mathrm{Zn}$, no correlation between the hardness values and the depth force has been found.

\subsubsection{Alloys from $\mathrm{Cu}-\mathrm{Fe}-\mathrm{Zn}$ system}

For the alloys of this system, no correlation has been observed between its hardness and the machining behavior. All the alloys exhibit a $\alpha+\beta$ structure with an iron rich phase.

\subsection{Chip class}

In order to evaluate the effect of chemical composition on the chip class, chips obtained during turning operations were classified according to the ISO 3685:1993.

The alloys produced in this work drive to the formation of different chips types, from short and discontinuous chips, elemental chips and loose arc chips (types 7.1 and 6.2, respectively), even to tubular and washer-type helical chips (types 2 and 4, respectively). Fig. 7 presents some of the chips obtained after machining the specimens of brasses alloys, under the conditions related on the Section 2.

Every alloy with a lead content equal or higher than $0.95 \%$, independently of the presence of other alloying elements, reveal a class chip type of 7.1 or 6.2. The unique exception concerns to the alloy no. 26 (with $0.02 \% \mathrm{~Pb}$ ), the only to present a $\beta+\gamma$ structure caused by the combination of higher aluminium content and a lower $\mathrm{Cu} / \mathrm{Zn}$ ratio.

Most of the pure alloys produced in laboratory present washer-type helical chips (4.3, 4.2 and 4.1 type).

According to literature $[7,13], \beta$ phase is responsible for short and discontinuous chips however, the obtained results show that alloys with a totally $\beta$ phase structure can only produce the type of chips mentioned above if lead is present, otherwise the chips belong to washer-type helical and tubular chips.

The presence of high tin contents in brasses leads to $\gamma 1$ phase formation. Alloys that exhibit in their microstructure this phase combined with $\alpha$ phase present washer-type helical chips, long or short (4.1 and 4.2 type). However, if $\gamma 1$ phase is mixed with $\beta$ phase the alloys have chips of 2.2 type-short tubular chip.

The studied alloys of the $\mathrm{Cu}-\mathrm{Fe}-\mathrm{Zn}$ system with lower iron contents, (near $0.5 \%$ ), show snarled washer-type helical chips (4.3 type), for the two $\mathrm{Cu} / \mathrm{Zn}$ ratios studied. However, 
higher iron content $(0.9 \%)$ modifies the chips class driving to snarled ribbon chips.

Machining of alloys of the $\mathrm{Al}-\mathrm{Cu}-\mathrm{Zn}$ system with a $\alpha+\beta$ structure leads to snarled washer-type helical chips. The increase of aluminium, with the formation of a $\beta$ phase structure, is responsible for snarled chips, not helical but tubular. Additional Al, promotes the development of the $\gamma$ phase and leads to the production of chips similar to those obtained during commercial alloys machining, loose arc chips.

\section{Conclusions}

The results of the present work enabled the establishment of several relationships concerning the influence of the chemical composition and the hardness on the different components of cutting forces. The suggested mathematical expressions show not only the primordial effect of lead in the machinability behaviour, already indicated by several authors, but also the effect of another alloying elements usually present in brasses composition. Commercial alloys, with and without additions, show lower values of cutting forces (Fz) than the pure alloys of the studied ternary systems. However, in some cases, they present similar and higher values of feed and depth forces. The cutting forces demanded by the pure alloys of the ternary systems studied in this work are affected by the type of alloying element present, as well as by its content. In the alloys from the $\mathrm{Cu}-\mathrm{Sn}-\mathrm{Zn}$ system, the lowest values of cutting and feed forces have been obtained for tin contents that drive to a $\beta+\gamma 1$ structure. On the other hand, the presence of aluminium in alloys of the $\mathrm{Al}-\mathrm{Cu}-\mathrm{Zn}$ system, has an opposite effect of tin, rising the cutting force as it is content increases. In this ternary system, the highest values of Fz, have been obtained for alloys with a $\beta+\gamma$ or only $\beta$ structures. Concerning $\mathrm{Cu}-\mathrm{Fe}-\mathrm{Zn}$ pure alloys, no relationship was found between the iron content and the machinability parameters.

No significant correlations were found between the cutting forces and the chemical composition, when expressed in terms of effective copper content. However, a relationship seems to occur concerning the feed force on commercial alloys. Further studies are needed to explain clearly such different behaviour.

Hardness of ternary pure alloys, namely of the $\mathrm{Cu}-\mathrm{Sn}-\mathrm{Zn}$ and $\mathrm{Al}-\mathrm{Cu}-\mathrm{Zn}$ systems, seems to play an important role in machining characteristics. However, no correlation has been found between this property and the machining behaviour of commercial brasses.

Concerning chip class, only one of the ternary pure alloys, from the $\mathrm{Al}-\mathrm{Cu}-\mathrm{Zn}$ system, reveals a loose arc chips class, type 6.2, similar to that obtained in the machining of commercial brasses. The literature refers that the presence of $\beta$ phase is responsible for promoting the chip fragmentation; however, the obtained results show that this is true only if lead is present, otherwise the chips belong to washer-type helical or tubular chip classes.

\section{Acknowledgment}

The authors acknowledge the Mechanical Engineer Paulo Matos for his participation in the machinability tests at University of Aveiro.

\section{References}

[1] Influence des conditions de refroidissement sur les caractéristiques mécaniques et la structure micrographique du laiton au plomb. Cuivre Laitons Alliages 62 (1961) 27-31 (in French).

[2] A. Szyszkowski, Les principaux laitons au plomb et leurs usages, Centre Belge d' Information du Cuivre, Publication no. 53/V, Symposium "Les laitons", 1973 (in French).

[3] R. Ragon, M. Stucy, Influence du plomb sur l'usinabilité des alliages cuivreux pour robinetterie, Fonderie-Fondeur d' aujourd' hui 170 (1997) 8-15 (in French).

[4] A. Saigal, P. Rohatgi, Machinability of cast lead free yellow brass containing graphite particles, AFS Trans. 104 (1996) 225228.

[5] L. Whiting, P. Newcombe, M. Sahoo, Casting characteristics of red brass containing bismuth and selenium, AFS Trans. 103 (1995) 683-691.

[6] D. Twarog, Modified red brass with bismuth and selenium: research results, AFS Trans. 103 (1995) 451-461.

[7] L' usinage des alliages cuivreux. Fonderie-Fondeur d' aujourd' hui 267 (1975) 12-16 (in French).

[8] A. French, Improved free-machining leaded brass, J. Inst. Met. 101 (1973) 125-137.

[9] P.-J. Le Thomas, D. Arnaud, Influence des impuretés sur les propriétés des laitons, Fonderie 162 (1959) 323-325 (in French).

[10] D. Peters, New bismuth/selenium red brass alloys solve lead concerns, Mod. Casting 87 (1997) 57-59.

[11] L. Whiting, M. Sahoo, Modified red brass with bismuth: a literature review analysis, AFS Trans. 103 (1995) 395-413.

[12] D. Davies, Improved free-machining leaded brasses, J. Inst. Met. 101 (1973) 125-137.

[13] M. Cook, E. Davis, Free-turning brass, J. Inst. Met. 69 (1940/41) 65-79.

[14] A. Louvo, T. Rantala, V. Rauta, L'effet de la composition sur la microstructure de coulée de laitons $\alpha+\beta$ et son contrôle par microordinateur, Fonderie-Fondeur d' aujourd' hui 48 (1985) 44-46 (in French).

[15] P. Rohatgi, D. Nath, S. Ray, Casting characteristics of machinable lead-free copper graphite alloys, AFS Trans. 93-104 (1993) 4958.

[16] B. Lunn, J. Christensen, Some observations on the notch impact test and free properties of leaded brasses, J. Inst. Met. 98 (1970) 164-168.

[17] L. Higley, E. Cole, H. Kenworthy, J. Holman, Effect of lowering tin content of secondary red brass, AFS Trans. 71-21 (1971) 157160.

[18] D. Peters, Bismuth Modified Cast Red Brasses to Meet U.S. Drinking Water Standards, Copper Development Association, 1995.

[19] D. Davies, Bismuth in copper and copper base alloys: a literature review. Technical Report, Copper Development Association, 1993.

[20] Y. Li, T. Ngai, W. Xia, Y. Long, D. Zhang, A study of aluminium bronze adhesion on tools during turning, J. Mater. Process. Technol. 138 (2003) 479-483

[21] M. Marcos-Barcarena, M. Sebastian Perez, J. Contreras-Samper, M. Sanchez-Carrilero, M. Sanchez-Lopez, J. Sanchez-Sola, Study of roundness on cylindrical bars turned of aluminium-copper alloys UNS A92024, J. Mater. Process. Technol. 162-163 (2005) 644648. 